\title{
Interlaminar mechanical properties of carbon fiber reinforced plastic laminates modified with graphene oxide interleaf
}

\author{
Huiming Ning, ${ }^{\mathrm{a}}$ Jinhua Li, ${ }^{\mathrm{b}}$ Ning $\mathrm{Hu},{ }^{\mathrm{a}, \mathrm{b}} *$ Cheng Yan, ${ }^{\mathrm{c}}$ Yaolu Liu, ${ }^{\mathrm{a}}$ Liangke $\mathrm{Wu},{ }^{\mathrm{a}}$ \\ Feng Liu ${ }^{d}$ and Jianyu Zhang ${ }^{a}$
}

${ }^{a}$ Department of Engineering Mechanics, College of Aerospace Engineering, Chongqing Key Laboratory of Heterogeneous Material Mechanics, Chongqing University, Chongqing, 400044, China

${ }^{\mathrm{b}}$ Department of Mechanical Engineering, Chiba University, 1-33 Yayoi-cho, Inage-ku, Chiba City, Chiba 263-8522, Japan

${ }^{\mathrm{c}}$ School of Chemistry, Physics and Mechanical Engineering, Science and Engineering Faculty, Queensland University of Technology, 2 George Street, GPO Box 2434, Brisbane, Australia

${ }^{\mathrm{d}}$ College of Mechanical and Vehicle Engineering, Hunan University, Changsha 412008, P.R. China

*Corresponding author E-mail: ninghu@cqu.edu.cn or huning@ faculty.chiba-u.jp Phone number: +86-23-65102527, Fax number: +86-23-65102421 
Abstract: By taking the advantage of the excellent mechanical properties and high specific surface area of graphene oxide (GO) sheets, we develop a simple and effective strategy to improve the interlaminar mechanical properties of carbon fiber reinforced plastic (CFRP) laminates. With the incorporation of graphene oxide reinforced epoxy interleaf into the interface of CFRP laminates, the Mode-I fracture toughness and resistance were greatly increased. The experimental results of double cantilever beam (DCB) tests demonstrated that, with $2 \mathrm{~g} / \mathrm{m}^{2}$ addition of GO, the Mode-I fracture toughness and resistance of the specimen increase by $170.8 \%$ and $108.0 \%$, respectively, compared to those of the plain specimen. The improvement mechanisms were investigated by the observation of fracture surface with scanning electron microscopies. Moreover, finite element analyses were performed based on the cohesive zone model to verify the experimental fracture toughness and to predict the interfacial tensile strength of CFRP laminates. 


\section{Introduction}

Owing to their high specific modulus and strength, carbon fiber reinforced plastic (CFRP) have attracted great scientific and industrial interest and are extensively used in many structural applications including aerospace, automobile, civil and marine structures where high performance and lightweight of structures are essential [1, 2]. However, as a laminated structure, CFRP laminates are extremely susceptible to crack initiation and propagation along the laminar interfaces. Delamination is one of the most prevalent life-limiting crack growth mode, causing severe reductions in in-plane strength and stiffness [3], and even catastrophic failure. Consequently, it is critical to develop new strategies to improve the interlaminar strength of CFRP.

In order to improve the interlaminar mechanical properties of CFRP laminates, various through-thickness reinforcement methods such as transverse stitching [4], z-pinning [5] and three-dimensional weaving [6] have been used, with proved effectiveness in alleviating delamination and subsequent buckling. However, the in-plane mechanical properties can be deteriorated to a certain extent.

With the advances in nanotechnology, nanofillers have been increasingly applied to the matrix, the surface of carbon fiber or the interlaminar interface of CFRPs to improve the interlaminar strength [7-12]. Among them, $\mathrm{SiO}_{2}$ particle [13], carbon black (CB) [14], nanofibers such as carbon nanotube (CNT) $[10,15]$ and vapor grow carbon fiber (VGCF) $[9,11]$ have been widely practiced. Recently, graphene [16], due to its high specific area and excellent mechanical [17], electrical [18], and thermal [19] properties, is recognized as potential reinforcement for improving mechanical [20-22], electrical [23, 24] and thermal $[25,26]$ properties of nanocomposites. For example, Rafiee et al. [27] found only a small 
amount (0.1 wt.\%) graphene can remarkably increase the tensile strength and fracture toughness up to $40 \%$ and 53\%, respectively in graphene platelets (GP)/epoxy nanocomposites. Zhao et al. [28] reported $150 \%$ increase of tensile strength and about 10 times increase of Young's modulus for graphene/poly(vinyl alcohol) (PVA) composites at a graphene loading of 1.8 vol.\%. Currently, producing high purity monolayer graphene is very costly. In addition, it is still a technical challenge to disperse graphene evenly into polymers. On the other hand, graphene oxide, consisting of graphene and other functional groups such as hydroxyl, epoxide, carbonyl and carboxylic, is easy to fabricate at low cost and possesses many physical properties of graphene. The functionalities on the surface of graphene oxide can enhance the dispersion of graphene oxide in polymeric matrices and the interfacial interaction between graphene and polymeric matrices [29-31]. Extensive works have demonstrated that graphene oxide (GO) sheets are potentially effective reinforcements in polymer [32-37], ceramic [38-40] composites. However, up to date, GO as mechanical reinforcement nanofillers for FRPs laminates has not been fully explored. For example Mannov et al. [41] investigated the residual compressive properties of both CFRP and GFRP composites with thermally reduced graphene oxide (TrGO). The residual compressive strength was increased about $35 \%$ and $55 \%$ in the CFRP and GFRP laminates. Yavari et al. [42] introduced TrGO sheets into the GFRP composites and observed 1200-fold and 3-5 fold increase in flexural bending and uniaxial tensile fatigue life respectively. It was found that the fatigue life for the specimens with TrGO spray-coated onto the glass fibers was much longer than the corresponding specimens with TrGO uniformly dispersed in the epoxy resin. Zhang et al. [43] directly introduced graphene oxide sheets dispersed in the fiber sizing which is used to coat on the surface of individual 
carbon fibers. They observed that the interfacial shear strength (IFSS) of those composites could obtain about $70.9 \%$ and $36.3 \%$ improvements compared with that of the virgin carbon fiber composites and the commercial sizing modified carbon fiber composites, respectively. In spite of the above mentioned progresses, to our best knowledge, there is no report about employing GO as interleaf inserted into the interlaminar interface of FRPs. Furthermore, its effects on the interlaminar fracture toughness were not investigated.

In this study, the GO sheets were first dispersed in the epoxy resin, and then the GO reinforced epoxy (GO-epoxy) was directly introduced into the interface of CFRP sublaminates to improve the interlaminar mechanical properties of CFRP laminates. Double cantilever beam (DCB) tests were performed to investigate the synergetic effect of GO and epoxy interleaf on the interlaminar fracture toughness of CFRP laminates. Moreover, to verify the experimental results, finite element analyses (FEA) was conducted and indicated the enhanced interlaminar tensile strengths. The toughening mechanisms were investigated in detail by the observation of fracture surfaces.

\section{Experiments}

\subsection{Materials}

Unidirectional CFRP prepregs (TOHO TENAX Co., Ltd, Japan) were employed to fabricate the CFRP laminates, where the diameter of carbon fiber (CF) was $7 \mu \mathrm{m}$, and the volume content of $\mathrm{CF}$ was $65 \%$. Insulating bisphenol-F epoxy resin (JER806) was purchased from Japan Epoxy Resins Co., Ltd, Japan. GO used in this study was prepared by oxidation of graphite powder using a modified Hummer's method as reported in [44, 45], Scanning electron microscope (SEM) image of the GO flakes was shown in Figure 1(a), the 
platelets were observed to be several to dozens of micrometers in size. Figure 1(b) shows the typical transmission electron microscopy (TEM) image of the GO flakes. Figures 1(c) and 1(d) illustrate the high-resolution TEM (HRTEM) image and its FFT image of GO monolayer which reveals small ripple and honeycomb structure of GO monolayer. Note that the ripple structure in GO sheet could play an important role in enhancing mechanical interlocking and load transfer with the matrix [27]. Figure 1(e) presents the atomic force microscopic (AFM) image of GO flakes. The thickness of the as-prepared GO flakes were around 1-2 nm, which indicates that the as-prepared GO flakes were composed of 1-2 layers of individual GO sheet. The measured thickness of individual GO sheet used in this study was larger than the theoretical value of $0.35 \mathrm{~nm}$ [46] for single layer graphene which may be resulted from the oxygen-containing groups, such as epoxy and hydroxyl groups, on the GO surfaces. The X-ray photoelectron spectroscopy (XPS), as shown in Figure 2, was employed to evaluate the quantification of the oxygen-containing functional groups on the surface of GO. The XPS spectra were taken by using an Axis Ultra DLD X-ray photoelectron spectrophotometer (Kratos Aanlytical Ltd) equipped with a mono Al K $\alpha$ X-ray source $(\mathrm{h} v=1486.71 \mathrm{eV})$, operated at a $75 \mathrm{~W}$ emission power and a $15 \mathrm{kV}$ acceleration voltage. The base operating pressure in the XPS chamber was better than $10^{-9}$ Torr. The C1s XPS spectrum of GO was fitted and assigned into three corresponding carbon atoms components at different positions. The binding energies at $284.5 \mathrm{eV}, 286.7$ $\mathrm{eV}$ and $288.3 \mathrm{eV}$ are assigned to $\mathrm{C}-\mathrm{C}, \mathrm{C}-\mathrm{O}$ and $\mathrm{C}=\mathrm{O}$ respectively. These assignments agree with previous works $[47,48]$. The presence of various oxygen containing functional groups enables the obtained GO flakes to disperse well in polymeric matrices and enhances the interfacial interaction between $\mathrm{GO}$ and polymeric matrices. 


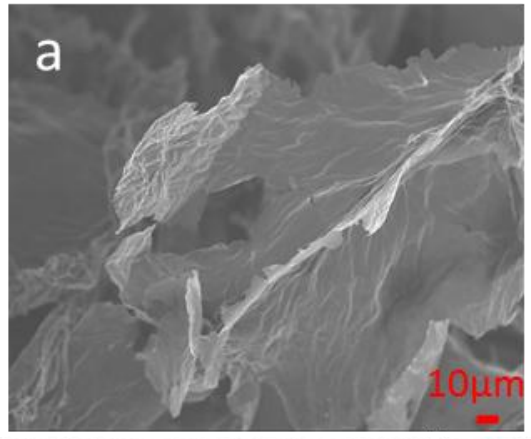

b
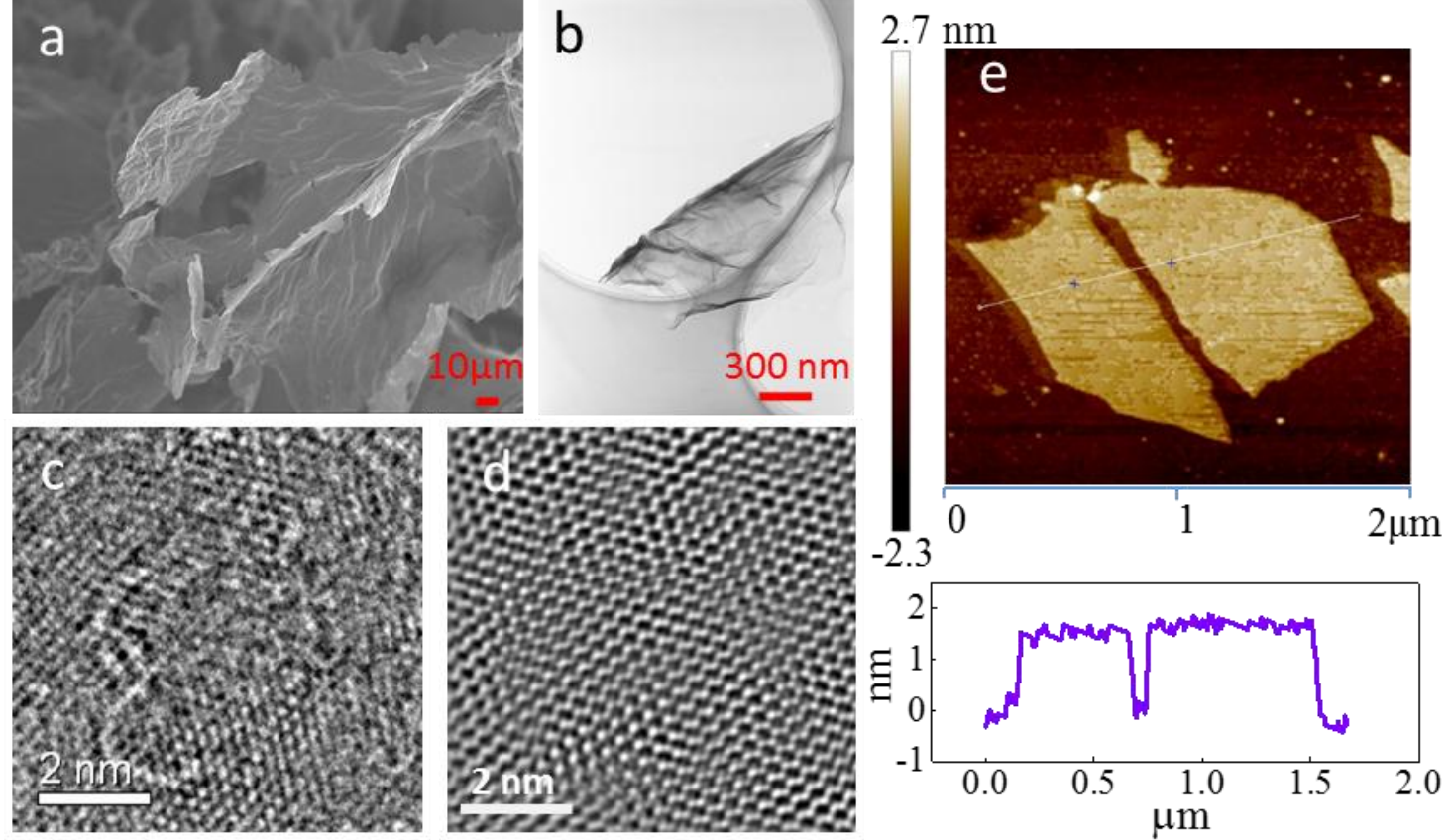

Figure 1. Characterization of GO: (a) SEM image of GO flakes; (b) Bright-field TEM image of a typical GO flake deposited on a standard TEM grid; (c) and (d) HR-TEM image and its FFT image reveal small ripple and honeycomb structure of GO; (e) Typical AFM image of the GO sheet with a height profile.

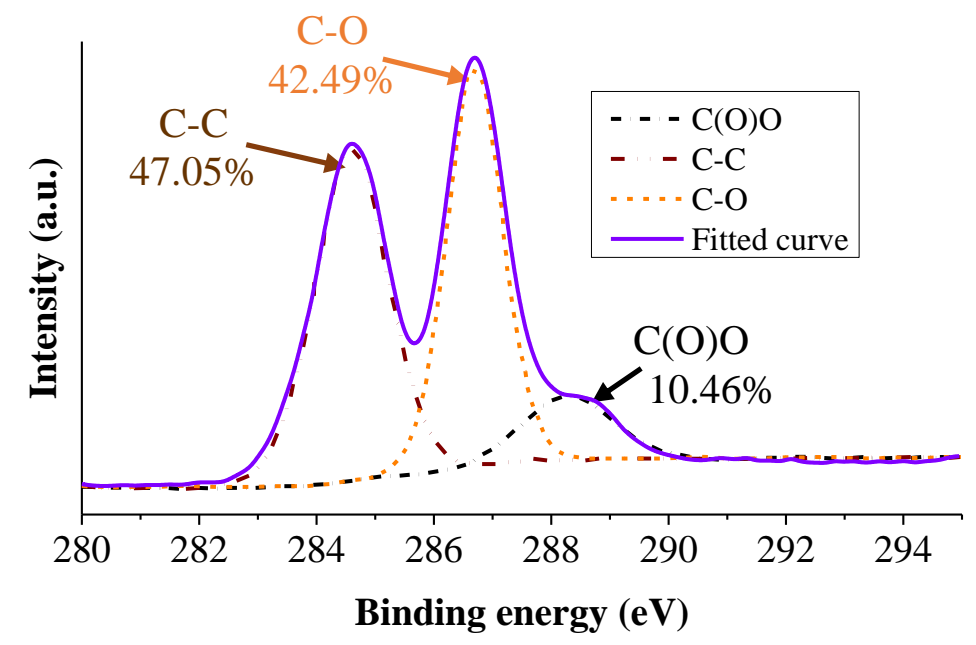

Figure 2. XPS C1s spectrum of GO sheets

\subsection{Fabrication of CFRP laminates toughened by GO-epoxy interleaf}

The GO reinforced epoxy paste serving as reinforcing interleaf was first fabricated. The 
corresponding fabrication process is illustrated in Figure 3. The prepared GO aqueous solution was dispersed into the polar aprotic solvent, $N, N$-Dimethylformamide (DMF, Wako Pure Chemical Industries Co., Ltd., Japan), using an ultrasonic dispersion machine (UH-600 SMT Co., Ltd., Japan) for $15 \mathrm{~min}$. Then, epoxy was poured into the GO and DMF solution, and the solution was stirred by a planetary centrifugal mixer at 2000 rpm for $10 \mathrm{~min}$. After that, the mixture was further processed by ultrasonic vibration for 15 min and mechanically stirred by planetary centrifugal mixer at 2,000 rpm for $10 \mathrm{~min}$ respectively to achieve a better GO dispersion. After heating the final mixture in a vacuum oven (AVO-250N, AS ONE Co., Ltd., Japan) at $90{ }^{\circ} \mathrm{C}$ for $12 \mathrm{~h}$ to remove the DMF solvent, the GO-epoxy paste was obtained. 24 pieces of CFRP prepregs were stacked together through a lay-up process to form two pieces of $\left[0^{\circ}\right]_{12}$ CFRP sublaminates. The obtained paste was evenly spread at one surface of each sub-laminate using a metallic roller. A polyimide film (Kapton, Toray Inc.) of $25 \mu \mathrm{m}$ thickness was put on one side of one sublaminate to create an initial crack. Finally, the above two sublaminates were bonded together at the GO-epoxy painted side by curing them in the hot press (SA-302, TESTER SANGYO Co., Ltd, Japan) at $130{ }^{\circ} \mathrm{C}$ and $0.7 \mathrm{MPa}$ for $4 \mathrm{~h}$, and then CFRP laminates reinforced by GO-epoxy interleaf were obtained.

To systematically investigate the effects of GO interleaf on the fracture toughness of CFRP laminates, 4 types of CFRP laminates with GO-epoxy interleaf were prepared, where the area density of GO was varied from $0 \mathrm{~g} / \mathrm{m}^{2}$ to $3 \mathrm{~g} / \mathrm{m}^{2}$ but the area density of epoxy was kept as an constant, i.e., $215 \mathrm{~g} / \mathrm{m}^{2}$. For simplicity, these CFRP laminates with GO-epoxy interleaf are referred as $\mathrm{GO}$, GO1, GO2 and GO3 respectively, where "GO" denotes the addition of GO-epoxy interleaf at the interface between two CFRP sublaminates, and the 
numbers, i.e., " $0,1,2$ and 3" represent the corresponding area density of GO in the unit of $\mathrm{g} / \mathrm{m}^{2}$. Moreover, CFRP laminates without interleaf, i.e., "Plain", was also prepared for reference. The average thicknesses of various CFRP laminates were listed in Table 1 which shows that the thickness of CFRP laminates increases only slightly with increasing addition of GO.

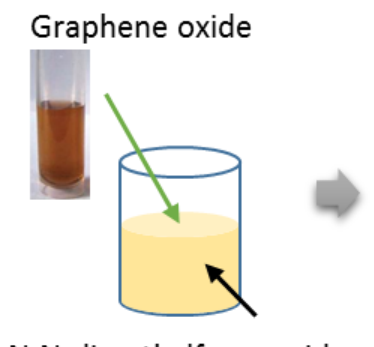

$\mathrm{N}, \mathrm{N}$-dimethylformamide

(DMF)

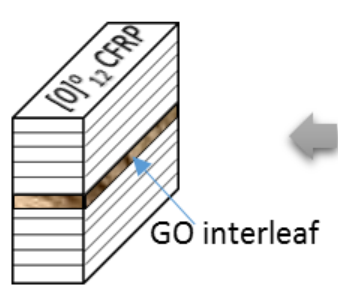

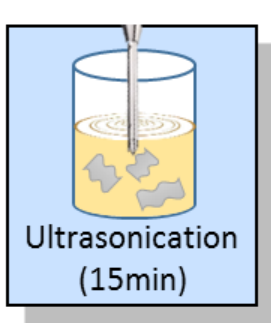
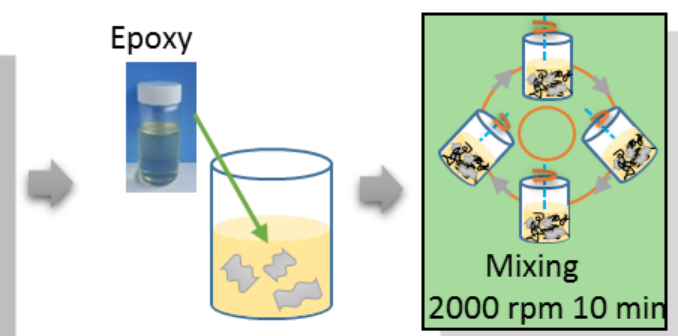

$2000 \mathrm{rpm} 10 \mathrm{~min}$

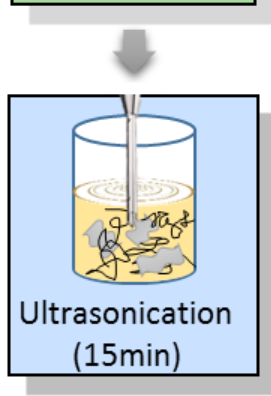

Figure 3. Schematic illustration of specimen fabrication process

Table 1. Average thicknesses of various CFRP laminates

\begin{tabular}{cccccc}
\hline Specimen & Plain & GO0 & GO1 & GO2 & GO3 \\
\hline $\begin{array}{c}\text { Average } \\
\text { thickness (mm) }\end{array}$ & 3.131 & 3.134 & 3.138 & 3.143 & 3.148 \\
\hline
\end{tabular}

\section{$2.3 \mathrm{DCB}$ tests}

To evaluate the Mode-I interlaminar fracture toughness, DCB test was performed using a universal material testing machine (5982, Instron Co., United States) at room temperature according to a Japanese Industrial Standard (JIS K 7086) [49]. 
As schematically illustrated by Figure 4, DCB specimens were cut from the above fabricated laminates. For each type of laminate, three specimens were prepared. Here, $L, H$ and $B$ are the length, half height and width of the specimen, respectively. Initial crack length $a_{o}$ indicates the distance between initial crack tip and loading point in the longitudinal direction. Crack increment $\Delta a$ denotes crack propagation, which can be measured by using the mark lines painted on the side surface of the specimen. Two aluminum tabs were attached to one end of the specimen to impose tensile load with a special apparatus through universal joints. The tensile load was applied at a crosshead speed of $0.5 \mathrm{~mm} / \mathrm{min}$. Tests were stopped when the increment of crack length $\Delta a$ reaches $40 \mathrm{~mm}$. The applied load $P$ and the crack opening displacement (COD) $\delta$ were recorded.

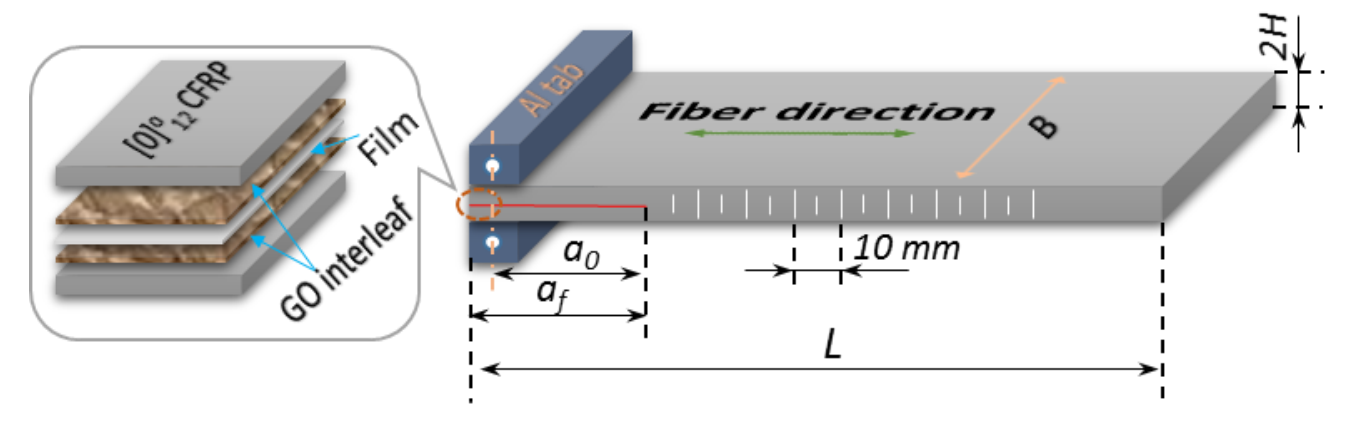

$L=150 \mathrm{~mm} ; B=20 \mathrm{~mm} ; 2 H=3.13 \sim \mathrm{mm}$, Initial crack length $a_{o}=34 \mathrm{~mm}, a_{f}=40 \mathrm{~mm}$

Figure 4. Schematic illustration of specimen for DCB tests

By using the compliance calibration method in classical fracture mechanics, Mode-I interlaminar fracture toughness can be calculated by the following equation [49]. 


$$
G_{\mathrm{IC}}=\frac{3}{2(2 H)}\left(\frac{P_{C}}{B}\right) \frac{\left(B \lambda_{0}\right)^{\frac{2}{3}}}{a_{1}}
$$

Here, $P_{\mathrm{C}}$ is the critical load at the initialization of crack growth. $\lambda_{0}$ is the compliance of load-COD curve at crack initiation point. By using the experimental relationship between the crack length $a$ and the compliance $\lambda, a_{1}$ and $a_{0}$ can be fitted from the following equation,

$$
\frac{a}{2 H}=a_{1}(B \lambda)^{\frac{1}{3}}+a_{0}
$$

\section{Results and discussion}

\subsection{Mode-I interlaminar fracture toughness}

Representative Mode-I load-COD curves of five types of CFRP specimens (i.e., Plain, GO0, GO1, GO2, and GO3) are shown in Figure 5. The tensile load $P$ in the initial stage increases rapidly in a linear manner, then a sudden drop occurs due to crack propagating at the critical load point, followed by a nonlinear increase before the peak, and final decease. The critical loads $P_{\mathrm{C}}$ in load-COD curves of the above laminates are summarized in Figure 6. Obviously, the $P_{\mathrm{C}}$ of all the specimens with insertion of GO-epoxy interleaf (i.e., GO0, GO1, GO2 and GO3) are higher than that of the plain specimen except the GO0 specimen, which indicates the reinforcement effect of GO-epoxy interleaf. Moreover, with increasing GO addition at the interleaf, the $P_{\mathrm{C}}$ increases initially to a peak, and then decreases. The highest $P_{\mathrm{C}}$ is observed in GO2 specimen with $2 \mathrm{~g} / \mathrm{m}^{2} \mathrm{GO}$ addition in the interleaf, which is about $74.05 \%$ higher than that of Plain specimen. Note that the critical load $P_{\mathrm{C}}$ may not be 
the maximum load (see Figure 5), the maximum loads of the specimen with GO-epoxy interleaf are also much higher than that of the Plain specimen.

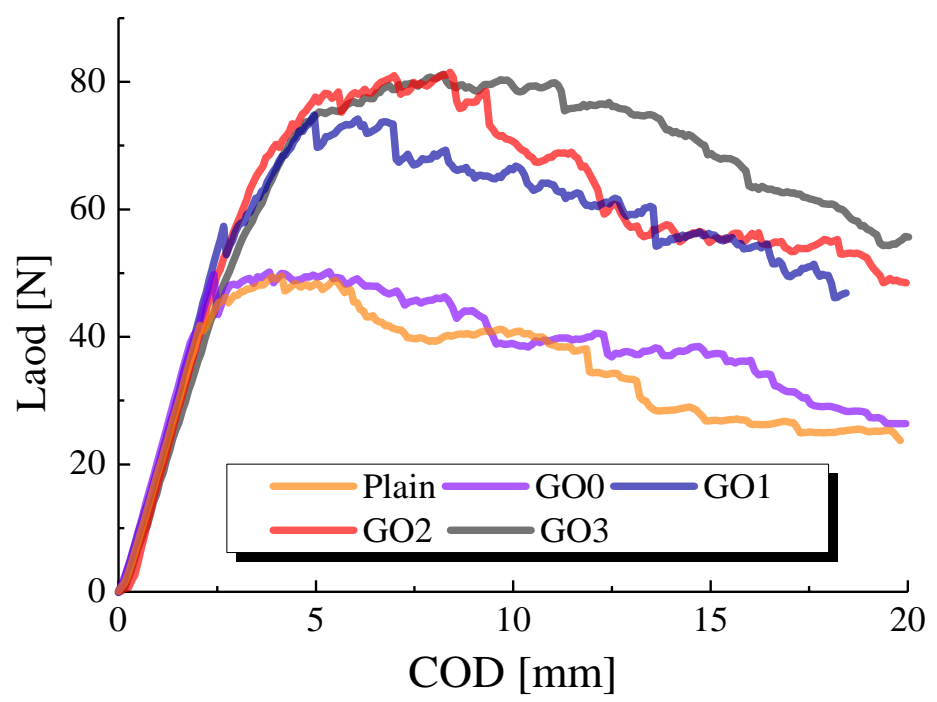

Figure 5. Representative load-COD curves for all kinds of specimens

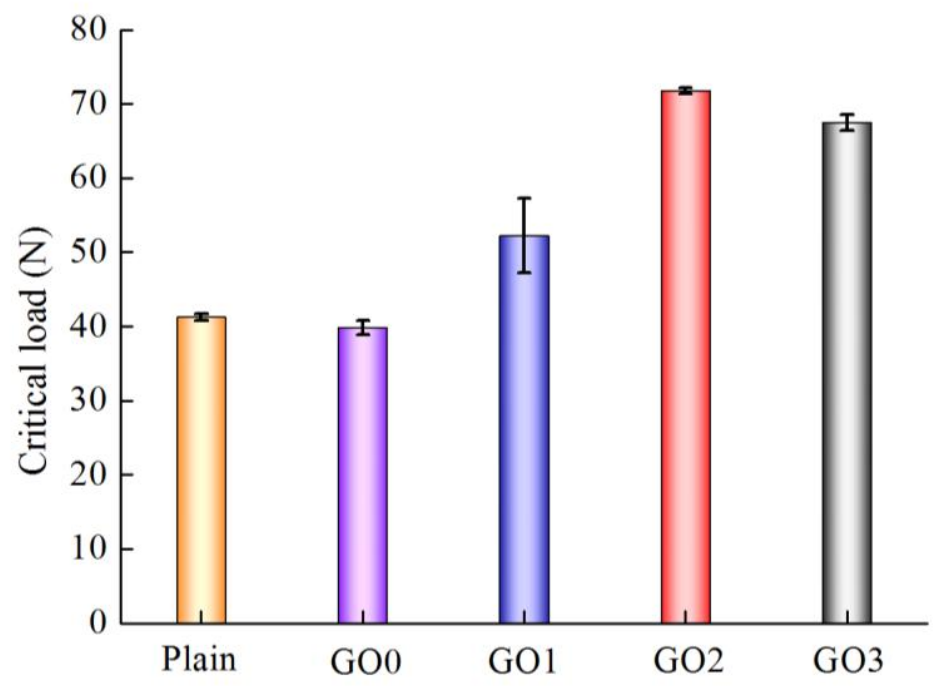

Figure 6. Critical load $P_{\mathrm{C}}$ for various specimens 
The relationship between fracture toughness and crack increment (i.e., $R$-curves) for all the tested laminates is illustrated in Figure 7. It can be found that the Mode-I fracture toughness increases with the crack length $\Delta a$ which is mainly attributed to fiber bridging on the fracture surface. The corresponding Mode-I fracture toughness $G_{\text {IC }}$ and fracture resistance $G_{\mathrm{IR}}$ are shown in Figure 8 . Note that $G_{\mathrm{IC}}$ was obtained from the crack initiation point of $R$-curve and $G_{\mathrm{IR}}$ was averaged by the values of 5 points when $\Delta a$ increases from 20 $\mathrm{mm}$ to $40 \mathrm{~mm}$. In Figure 8, the similar changing trend of fracture toughness with that of $P_{\mathrm{C}}$ can be found. Both $G_{\mathrm{IC}}$ and $G_{\mathrm{IR}}$ initially increase until to a maximum value and then decrease with the increasing addition of GO. The largest $G_{\mathrm{IC}}$ and $G_{\mathrm{IR}}$ are also observed in GO2 with $2 \mathrm{~g} / \mathrm{m}^{2} \mathrm{GO}$ addition in the interleaf, which are remarkably $170.8 \%$ and $108.0 \%$ higher than those of Plain, respectively (see Figure 9). It should be noted that, for the GO0 specimens with only epoxy in the interleaf, the $P_{\mathrm{C}}, G_{\mathrm{IC}}$ and $G_{\mathrm{IR}}$ were obtained as $39.83 \mathrm{~N}$, 0.163 and $0.443 \mathrm{KJ} / \mathrm{m}^{2}$, respectively, which were almost the same as those of the Plain specimen. This phenomenon is similar to that in [50].

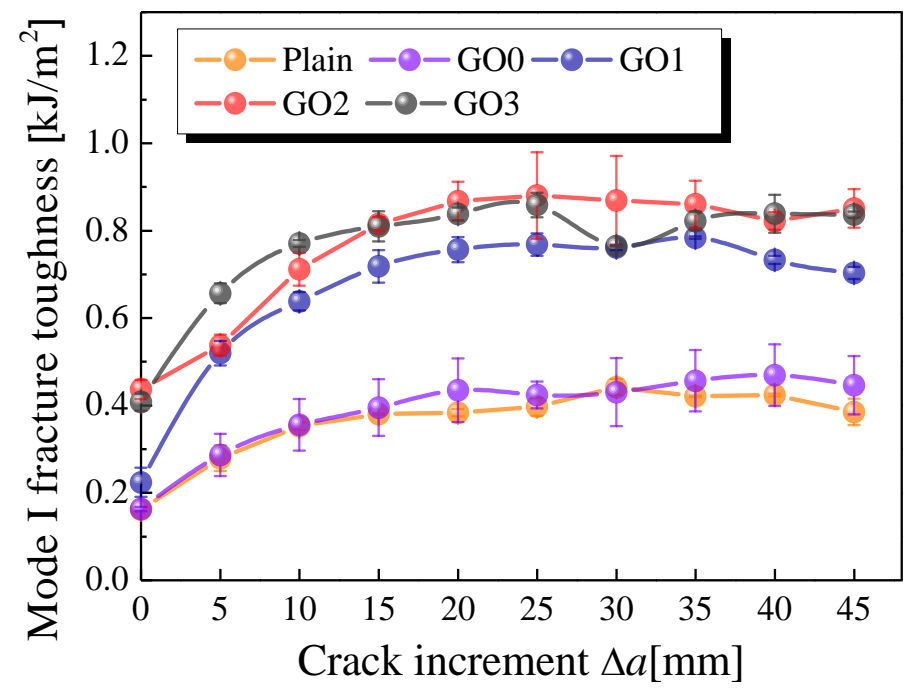

Figure 7. Comparison of R-curves for various specimens 


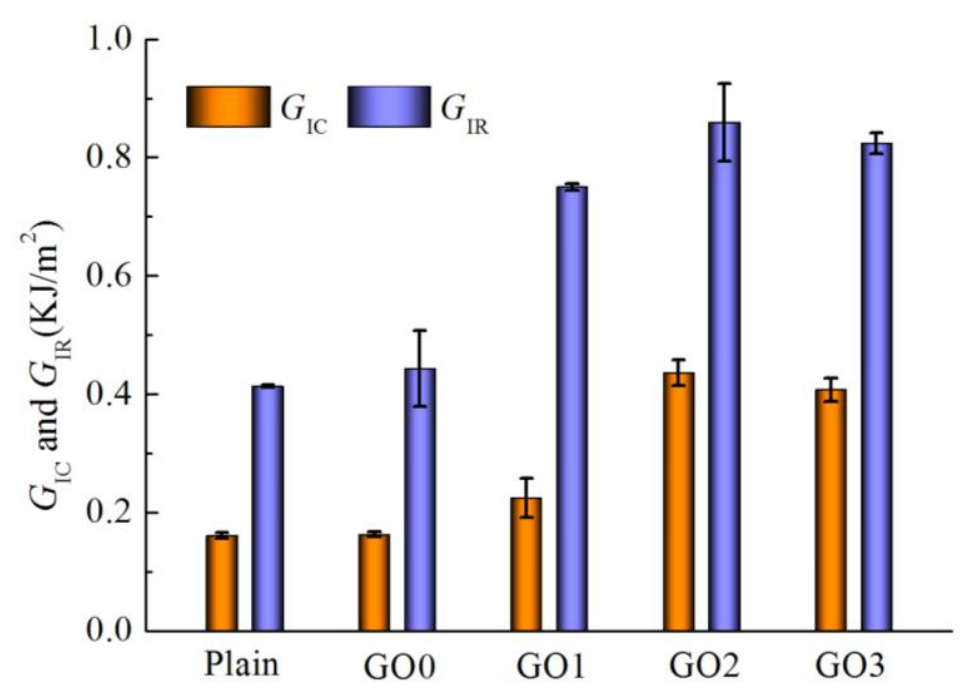

Figure 8. Comparison of Mode-I fracture toughness and resistance for various specimens

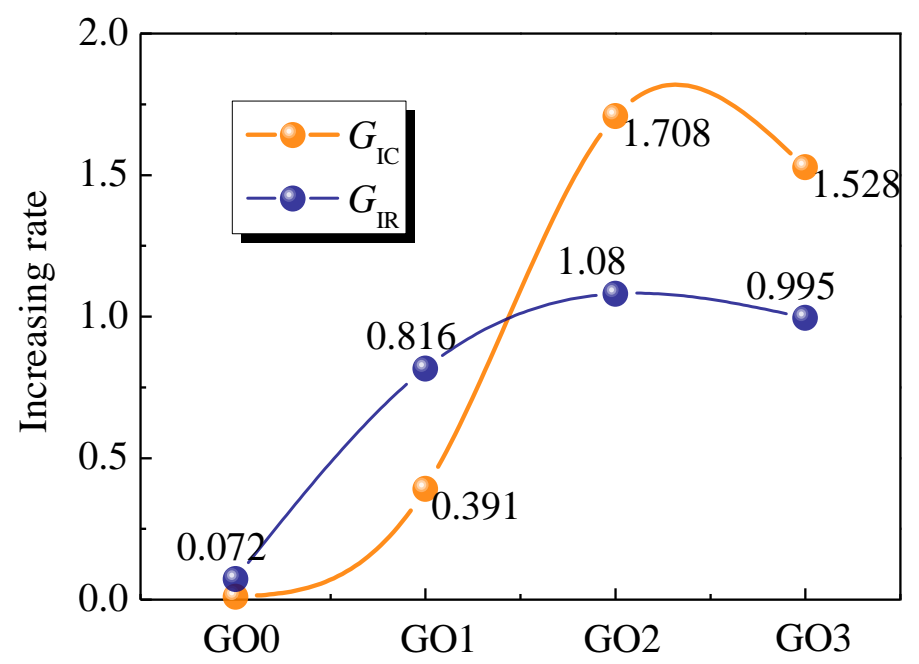

Figure 9. Increasing rates of fracture toughness and critical load for all kind of specimens.

The reinforcement effects of GO-epoxy interleaf on the Mode-I fracture toughness of CFRP laminates are compared with that of the other nanofillers as show in Table 2. It can be found that the increasing rate of $G_{\mathrm{IC}}$ in the present work is the highest one compared with the other results used, i.e., SiC whiskers [51], CSCNTs [52] and carbon black [53]. This value is even better than the best value of our previous work using VGCF [9], and is much 
better than carbon black using the same fabrication process. This demonstrates the remarkable reinforcement effects of GO-epoxy interleaf.

Table 2. Comparison of $G_{\mathrm{IC}}$ and $G_{\mathrm{IR}}$ for $\mathrm{GO} 2$ and other literatures.

\begin{tabular}{|c|c|c|c|c|c|c|}
\hline \multirow[t]{2}{*}{ Reinforced filler } & \multicolumn{2}{|c|}{$G_{\mathrm{IC}}\left(\mathrm{KJ} / \mathrm{m}^{2}\right)$} & \multicolumn{2}{|c|}{$G_{I R}\left(K J / m^{2}\right)$} & \multicolumn{2}{|c|}{ Increasing rate $(\%)$} \\
\hline & before & after & before & after & $G_{\text {IC }}$ & $G_{\mathrm{IR}}$ \\
\hline $\mathrm{GO}\left(2\left[\mathrm{~g} / \mathrm{m}^{2}\right]\right)$ & 0.161 & 0.436 & 0.413 & 0.859 & 170.8 & 108.0 \\
\hline $\mathrm{CB}\left(15\left[\mathrm{~g} / \mathrm{m}^{2}\right]\right)[53]$ & 0.161 & 0.242 & 0.413 & 0.779 & 50.3 & 88.6 \\
\hline $\operatorname{VGCF}\left(20\left[\mathrm{~g} / \mathrm{m}^{2}\right]\right)[9]$ & 0.221 & 0.432 & 0.489 & 0.616 & 95.5 & 26.0 \\
\hline $\mathrm{SiC}$ whisker [51] & 0.140 & 0.215 & 0.174 & 0.202 & 53.6 & 16.1 \\
\hline CSCNT $(1.8 w t \%)$ [52] & 0.076 & 0.125 & 0.086 & 0.170 & 64.5 & 97.7 \\
\hline
\end{tabular}

\subsection{Interlaminar tensile strength with FEA}

Finite element analysis was also employed to investigate the interlaminar mechanical properties of CFRP toughened by GO-epoxy interleaf. As shown in Figure 10(a), two-dimensional (2D) FEA model was built up using ABAQUS to simulate the processes of crack initialization and subsequent propagation in DCB specimens. The CFRP laminate was modeled by first-order plane strain element (CPE4I) with incompatible modes, which can not only overcome the shearing locking problem in the simulation of bending deformation when using the first-order element but also save computational cost compared to the second-order element. The interface between two sublaminates was modelled by zero thickness cohesive elements (COH2D4). To overcome strong numerical instabilities in crack propagation simulations, the cohesive element size along the length direction of beam was controlled to be smaller than $0.5 \mathrm{~mm}$ [54-56]. The total number of elements in the models was 2100 for DCB specimen. Table 3 shows the detailed material parameters of CFRP laminates in simulations. Table 4 lists material properties of cohesive element. Here, 
$K$ is the initial stiffness of cohesive elements before crack propagation. $G_{\mathrm{IC}}$ is critical fracture toughness obtained in DCB experiment tests. $N$ denotes the interlamianr tensile strength which is obtained through an inverse identification process. By matching the slope of the initial straight line and the peak load of the numerical load-COD curves to the experimental ones, the tensile strength of the CFRP laminates can be determined.

The comparison of numerical simulation and experimental test results is shown in Figures $10 \mathrm{~b}$ and 10c. Good consistence between numerical and experimental results can be observed. Moreover, as listed in Table 4, $N$ is enhanced with addition of GO-epoxy interleaf. The largest $N$ is also observed in GO2 specimen with $2 \mathrm{~g} / \mathrm{m}^{2} \mathrm{GO}$ addition, which is $66.7 \%$ higher than that of Plain. Therefore, the above experimental and numerical investigations provide clear evidences for the toughening effect of GO-epoxy interleaf on the Mode-I interlaminar mechanical properties of CFRP laminates including both interlaminar strength and fracture toughness.

Table 3. Material properties of CFRP laminates

\begin{tabular}{cccccc}
\hline$E_{11}$ & $E_{22}=E_{33}$ & $G_{12}=G_{13}$ & $G_{23}$ & $v_{12}=v_{13}$ & $v_{23}$ \\
\hline $138 \mathrm{GPa}$ & $10 \mathrm{GPa}$ & $6.0 \mathrm{GPa}$ & $3.7 \mathrm{GPa}$ & 0.27 & 0.45 \\
\hline
\end{tabular}

Table 4. Material properties of cohesive element

\begin{tabular}{ccccc}
\hline $\begin{array}{c}\text { Fracture } \\
\text { mode }\end{array}$ & Specimen & $K[\mathrm{GPa} / \mathrm{mm}]$ & $G_{\mathrm{IC}}\left[\mathrm{KJ} / \mathrm{m}^{2}\right]$ & $N[\mathrm{MPa}]$ \\
\hline \multirow{2}{*}{ Mode-I } & Plain & 350 & 0.161 & 30 \\
\cline { 2 - 5 } & $\mathrm{GO} 2$ & 350 & 0.436 & 50 \\
\hline
\end{tabular}




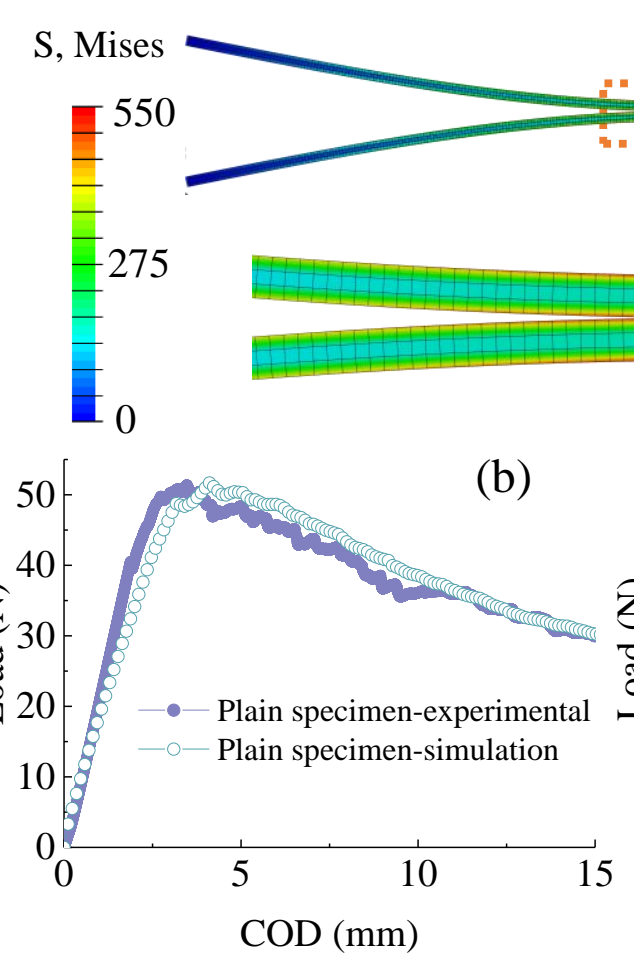

(a)

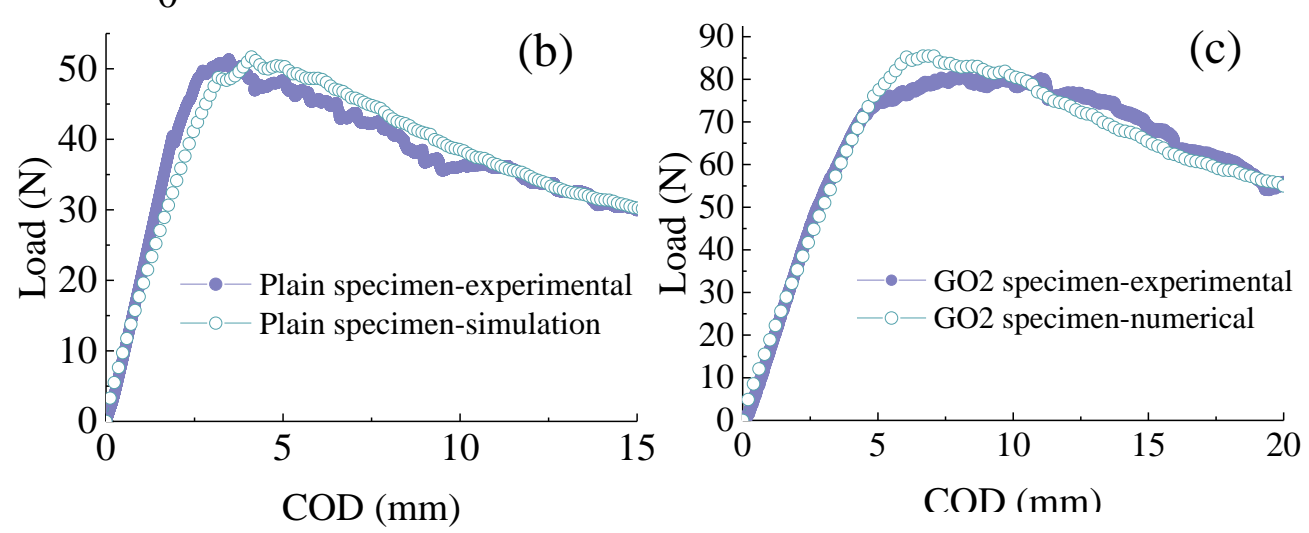

Figure 10. FEA details: (a) FEA models of DCB specimen; (b) and (c) Comparison of numerical and experimental load-COD curves of Plain specimen and GO2 specimen.

\subsection{Improvement mechanism}

It is well known that the fracture toughness of CFRP laminates is mainly determined by two key points, i.e., the toughness of matrix and the interfacial strength between carbon fiber and matrix. We will explore them in the following.

For the first point, many studies have demonstrated that GO can effectively improve the toughness of epoxy resin at low weight fractions of GO (usually less than $1.0 \mathrm{wt} \%$ ) [36, 57, 58]. For example, Wan et al. [36] found that there was $26 \%$ improvement in $K_{\text {IC }}$ value for epoxy composite with the optimal addition of $0.25 \mathrm{wt} \%$ of GO. Bortz et al. [58] reported the enhancement of $105.4 \%$ in Mode-I fracture toughness through the addition of $0.5 \mathrm{wt} \%$ of GO to an epoxy system. They also found that doubling the GO addition to 1.0 
$\mathrm{wt} \%$ revealed a saturation of the toughening effect. The weight fractions of GO in the GO-epoxy paste in this study are $0.465 \mathrm{wt} \%, 0.93 \mathrm{wt} \%$ and $1.395 \mathrm{wt} \%$ for GO1, GO2 and GO3 specimens respectively which are reasonable compared with that in [58]. Note that, the epoxy resin would also leak into the GO-epoxy interleaf from the CFRP prepregs during the CFRP curing process, therefore, the weight fractions of GO in the GO-epoxy interleaf could be further lower than that in the GO-epoxy paste. Consequently, the epoxy matrix of CFRP laminates near the interleaf will be toughened by the addition of GO with a fracture stress reaching to $63 \mathrm{GPa}$ as predicted by Monte Carlo simulations in [59]. The intrinsic excellent mechanical properties, the large surface area and specific wrinkled surface of the GO sheets combined with their anticipated strong interfacial bonding between GO and epoxy can be ascribed to the toughening mechanism. In addition, the functional groups on the surface of GO sheets also play a critical role in good dispersion of GO sheets in epoxy matrices and in enhancement of the interfacial interaction between GO and epoxy matrices [29]. As shown in Figure 11, a lot of H-bonds can be formed in the GO reinforced epoxy composites both between epoxy and the hydroxyl functional groups (Figure 11(a)) and intra- , inter-layer of GO sheets (Figure 11(b)). Those formed H-bond networks play a critical role to strength the interfacial interactions between GO and epoxy. Therefore, as highlighted in [30], a higher density of oxygen-containing groups on the surface of GO sheets leads to the decrease of elastic modulus of individual GO sheets, however, the groups also result in the increased bonds between the GO sheets and polymer molecules, and consequently the increase in overall mechanical properties. 


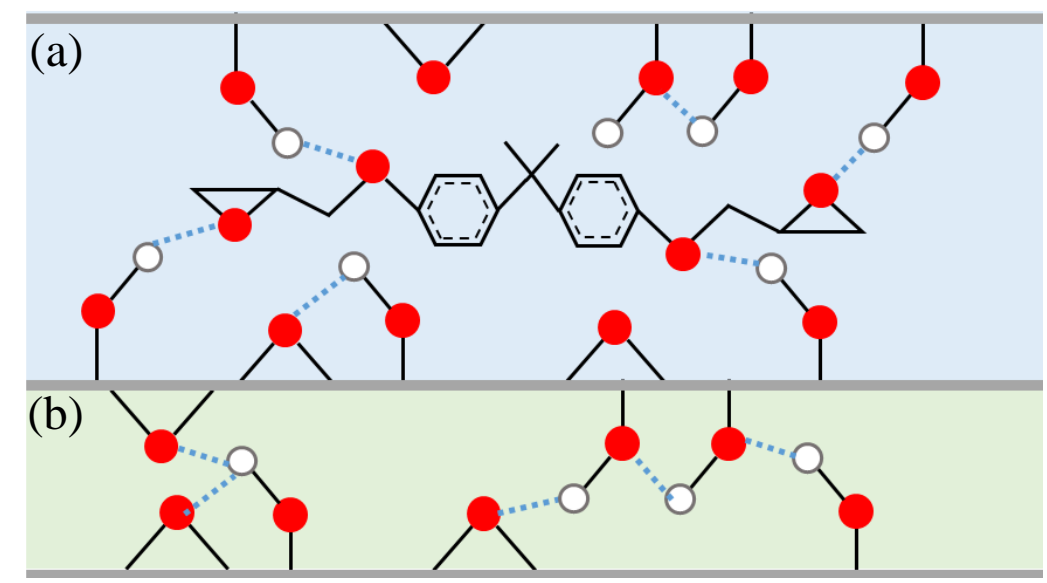

Figure 11. Schematic of various configurations of H-bonds formed: (a) Interface between GO sheet and epoxy molecule; (b) Intra-layer and inter-layer of GO sheets. (The horizontal gray lines denote the graphene sheet, while oxygen and hydrogen atoms are shown as red and white spheres, respectively. The H-bonds are denoted by dashed blue lines.)

For the second point, in order to investigate the interfacial strength between carbon fiber and epoxy matrix, fracture surfaces of the DCB tested laminates at the crack initiation position were observed by a scanning electron microscope (SEM) (JSM-6510A, JEOL Ltd.). Figure 12 shows the SEM fracture surface images of 4 types of laminates (i.e., Plain, GO1, GO2, GO3) after DCB tests under Mode-I loading. As shown in Figure 12(a), after fracture, many CFs were exposed with less epoxy resin covering them. The delamination of $\mathrm{CF}$ and epoxy matrix and the brittle fracture indicate the weak bonding between $\mathrm{CF}$ and epoxy matrix, and explains the relatively low Mode-I fracture toughness in Plain specimen. After addition of GO-epoxy interleaf, as shown in Figures 12(b), 12(c) and 12(d), CFs were embedded in GO reinforced epoxy resin and tightly bonded with it after fracture. This indicates that stronger interfacial adhesion between $\mathrm{CF}$ and epoxy resin for GO1, GO2 and GO3 specimens was realized after toughened by GO-epoxy interleaf. Better interfacial adhesion between epoxy resin and CF contributes to the improvement of Mode-I fracture toughness. This is also confirmed by high magnification SEM images which is performed 
at the typical region denoted by red dotted line in Figure 12. The high magnification SEM images clearly show that the interfacial strength of GO2 and GO3 are better than GO1. And GO2 possesses the best bonding strength between $\mathrm{CF}$ and epoxy matrix which are coincided with the fracture toughness results obtained in previous experiment tests. Moreover, more irregular and rough fracture surface also can be observed in the specimen toughened by GO-epoxy interleaf, this indicates that larger fracture area was created duo to the crack deflection and plastic deformation during crack propagation. Furthermore, many small irregular dimple structures can be observed in the fracture surfaces of the specimens with GO interleaf. The dimple structure is formed by the process in which an initial crack tilts and twists when it encounters a rigid GO. This leads to an increase in the total fracture surface area, requires higher driving force and consumes larger energy during crack propagation. All of these indicate the synergistic effect of both interleaf and CFPR laminates, and therefore support the higher Mode-I fracture toughness of GO1, GO2 and GO3 compared to that of Plain.

The fracture toughness of GO3 is slightly lower than that of GO2, which may be ascribed to the saturation of toughening effect of GO at high concentration. The overdose of GO may result in nanofiller aggregation in epoxy resin. As such aggregations will cause local stress concentration and detrimental to the toughness of epoxy and the adhesion strength between epoxy resin and CF. Therefore, the Mode-I fracture toughness of GO3 is lower than that of GO2 specimen. This is confirmed by Figure 13 which shows the high resolution SEM graphs of the fracture surface morphologies in different CFRP specimens. As shown in Figure 13, epoxy-coated GO flakes protruding out of the fracture surface can be clearly observed as indicated by the arrows in Figure 13, and they cause the formation of 
dimple structure in the fracture surface of GO reinforced specimen. The dispersion of GO can be roughly predicted. Obviously, the epoxy-coated GO flakes are evenly distributed on the fracture surface of $\mathrm{GO} 1$ and $\mathrm{GO} 2$ specimens, indicating good dispersion of $\mathrm{GO}$ in these specimens (Figures 13(a), (b)). However, for GO3 (Figure 13(c)), when the area density of GO in the interleaf increases to $3 \mathrm{~g} / \mathrm{m}^{2}$, aggregations of epoxy-coated GO flakes can be observed as marked by circles, suggesting the relatively poor dispersion of GO in the GO3 specimen. Therefore, the fracture toughness of GO3 tends to decrease compared to GO2.
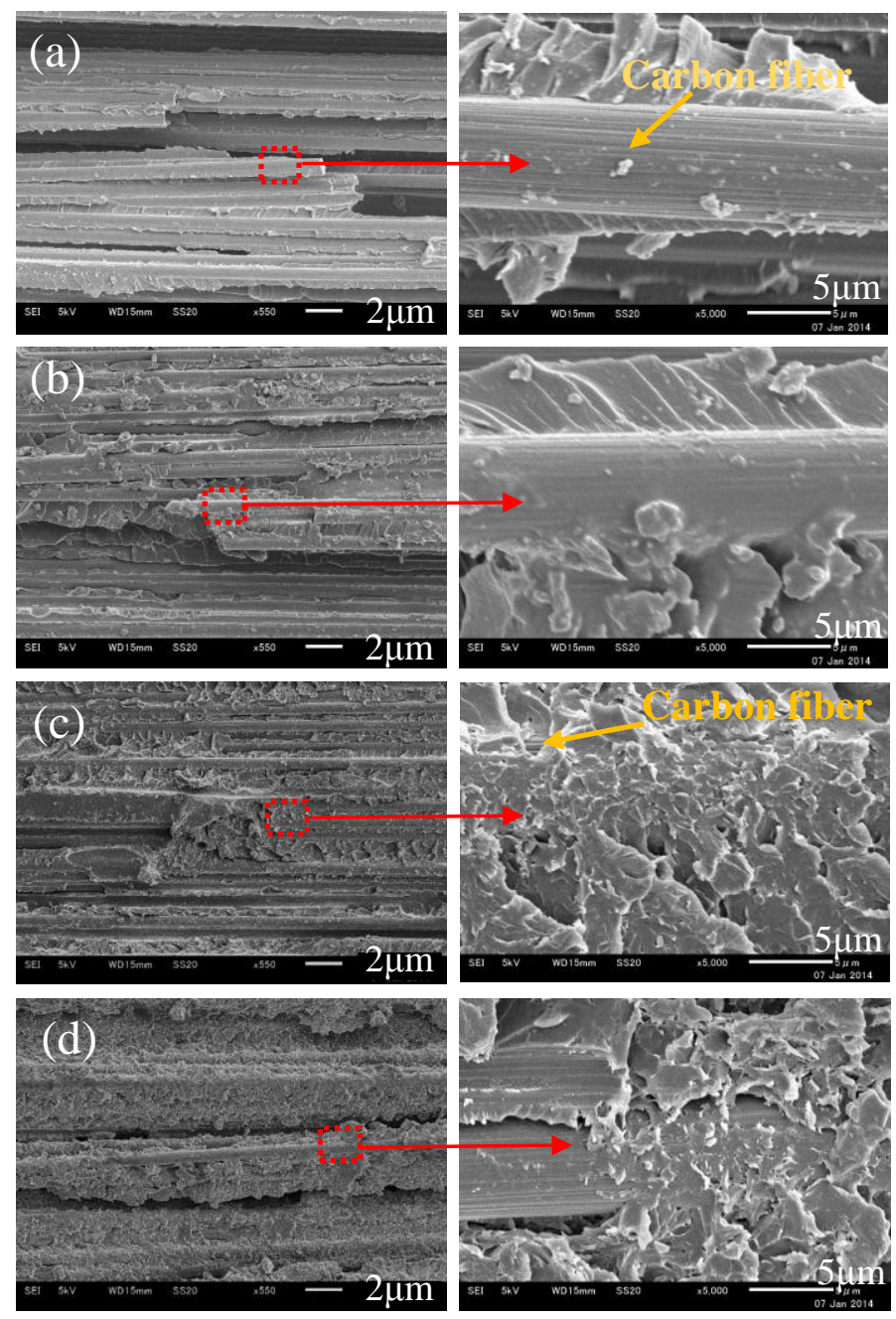

Figure 12. Fracture surfaces of Mode-I CFRP laminates: (a) Plain; (b) GO1; (c) $\mathrm{GO} 2$; (d) $\mathrm{GO} 3$ 

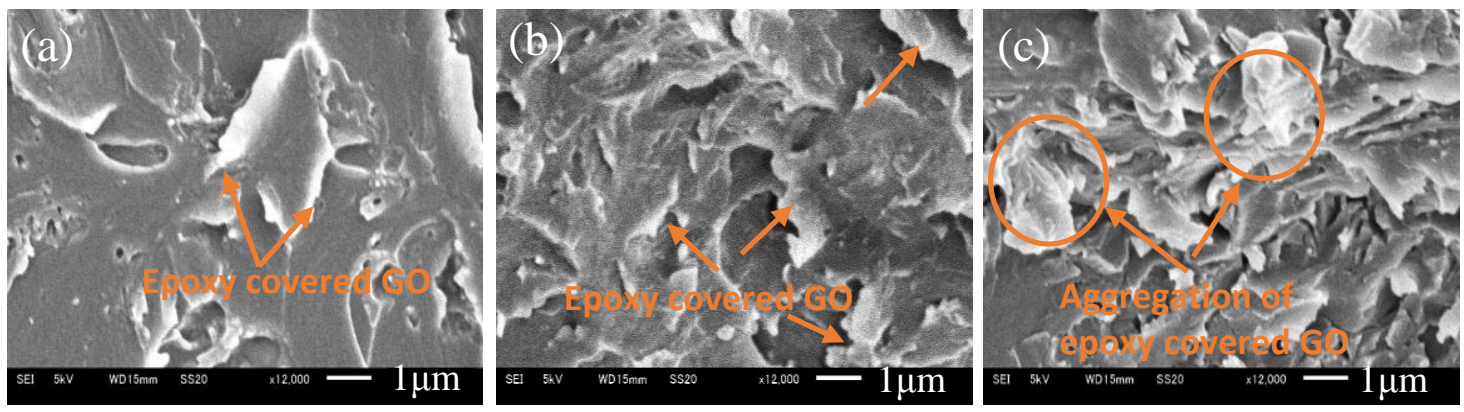

Figure 13. Graphene oxide dispersion condition: (a) GO1; (b) GO2; (c) GO3

\section{Conclusions}

In this study, the effect of GO reinforced epoxy interleaf on the interlaminar mechanical properties of CFRP laminates was systematically investigated. The experimental results of DCB tests demonstrated that the Mode-I fracture toughnesses of CFRP laminates can be improved significantly with introduction of GO reinforced epoxy interleaf into the interlaminar interfaces. Generally, as the GO loading increases, the fracture toughness initially increases up to a peak, and then decreases. The optimum area density of GO is 2 $\mathrm{g} / \mathrm{m}^{2}$, which brings about remarkable $170.8 \%$ and $108.0 \%$ increases in Mode-I fracture toughness and resistance, respectively. Furthermore, numerical simulations verified the experimental fracture toughness and successfully predicted the interfacial tensile strengths of the CFRP laminates. The observation of the fracture surfaces provided useful information about the toughening mechanisms.

\section{Acknowledgements}

This work is supported by the Research Funds from NSF of China (No.11372104). 


\section{References}

[1] Njuguna J, Pielichowski K, Alcock JR. Epoxy-based fibre reinforced nanocomposites. Adv Eng Mater. 2007;9(10):835-47.

[2] ALDERLIESTEN RC. Fatigue Crack Propagation and Delamination Growth in Glare. Netherlands: DUP Science; 2005.

[3] Sekine $\mathrm{H}, \mathrm{Hu} \mathrm{N}$, Kouchakzadeh M. Buckling analysis of elliptically delaminated composite laminates with consideration of partial closure of delamination. Journal of Composite Materials. 2000;34(7):551-74.

[4] Shu D, Mai Y-W. Effect of stitching on interlaminar delamination extension in composite laminates. Composites Science and Technology. 1993;49(2):165-71.

[5] Byrd LW, Birman V. Effectiveness of z-pins in preventing delamination of co-cured composite joints on the example of a double cantilever test. Composites Part B: Engineering. 2006;37(4):365-78.

[6] Mouritz A, Bannister M, Falzon P, Leong K. Review of applications for advanced three-dimensional fibre textile composites. Composites Part A: applied science and manufacturing. 1999;30(12):1445-61.

[7] Gojny FH, Wichmann MHG, Fiedler B, Bauhofer W, Schulte K. Influence of nano-modification on the mechanical and electrical properties of conventional fibre-reinforced composites. Composites Part A: Applied Science and Manufacturing. 2005;36(11):1525-35.

[8] Wichmann MHG, Sumfleth J, Gojny FH, Quaresimin M, Fiedler B, Schulte K. Glass-fibre-reinforced composites with enhanced mechanical and electrical properties - Benefits and limitations of a nanoparticle modified matrix. Engineering Fracture Mechanics. 2006;73(16):2346-59. 
[9] Li Y, Hori N, Arai M, Hu N, Liu Y, Fukunaga H. Improvement of interlaminar mechanical properties of CFRP laminates using VGCF. Composites Part A: Applied Science and Manufacturing. 2009;40(12):2004-12.

[10] Yokozeki T, Iwahori Y, Ishibashi M, Yanagisawa T, Imai K, Arai M, et al. Fracture toughness improvement of CFRP laminates by dispersion of cup-stacked carbon nanotubes. Composites Science and Technology. 2009;69(14):2268-73.

[11] Arai M, Noro Y, Sugimoto K-i, Endo M. Mode I and mode II interlaminar fracture toughness of CFRP laminates toughened by carbon nanofiber interlayer. Composites Science and Technology. 2008;68(2):516-25.

[12] Khan SU, Kim J-K. Improved interlaminar shear properties of multiscale carbon fiber composites with bucky paper interleaves made from carbon nanofibers. Carbon. 2012;50(14):5265-77.

[13] Jen M-HR, Tseng Y-C, Wu C-H. Manufacturing and mechanical response of nanocomposite laminates. Composites science and technology. 2005;65(5):775-9.

[14] Zhang D, Ye L, Deng S, Zhang J, Tang Y, Chen Y. CF/EP composite laminates with carbon black and copper chloride for improved electrical conductivity and interlaminar fracture toughness. Composites Science and Technology. 2012;72(3):412-20.

[15] Lee S-H, Kim H, Hang S, Cheong S-K. Interlaminar fracture toughness of composite laminates with CNT-enhanced nonwoven carbon tissue interleave. Composites Science and Technology. 2012;73:1-8.

[16] Novoselov KS, Geim AK, Morozov S, Jiang D, Zhang Y, Dubonos S, et al. Electric field effect in atomically thin carbon films. science. 2004;306(5696):666-9.

[17] Lee C, Wei X, Kysar JW, Hone J. Measurement of the elastic properties and intrinsic strength of monolayer graphene. science. 2008;321(5887):385-8. 
[18] Berger C, Song Z, Li T, Li X, Ogbazghi AY, Feng R, et al. Ultrathin epitaxial graphite: 2D electron gas properties and a route toward graphene-based nanoelectronics. The Journal of Physical Chemistry B. 2004;108(52):19912-6.

[19] Balandin AA, Ghosh S, Bao W, Calizo I, Teweldebrhan D, Miao F, et al. Superior thermal conductivity of single-layer graphene. Nano letters. 2008;8(3):902-7.

[20] Rafiee MA, Rafiee J, Yu ZZ, Koratkar N. Buckling resistant graphene nanocomposites. Applied Physics Letters. 2009;95(22):223103.

[21] Rafiee MA, Rafiee J, Srivastava I, Wang Z, Song H, Yu ZZ, et al. Fracture and fatigue in graphene nanocomposites. Small. 2010;6(2):179-83.

[22] Ramanathan T, Abdala AA, Stankovich S, Dikin DA, Herrera-Alonso M, Piner RD, et al. Functionalized graphene sheets for polymer nanocomposites. Nature nanotechnology. 2008;3(6):327-31.

[23] Stankovich S, Dikin DA, Dommett GH, Kohlhaas KM, Zimney EJ, Stach EA, et al. Graphene-based composite materials. Nature. 2006;442(7100):282-6.

[24] Pang H, Chen T, Zhang G, Zeng B, Li Z-M. An electrically conducting polymer/graphene composite with a very low percolation threshold. Materials Letters. 2010;64(20):2226-9.

[25] Yu A, Ramesh P, Itkis ME, Bekyarova E, Haddon RC. Graphite nanoplatelet-epoxy composite thermal interface materials. The Journal of Physical Chemistry C. 2007;111(21):7565-9.

[26] Teng C-C, Ma C-CM, Lu C-H, Yang S-Y, Lee S-H, Hsiao M-C, et al. Thermal conductivity and structure of non-covalent functionalized graphene/epoxy composites. Carbon. 2011;49(15):5107-16.

[27] Rafiee MA, Rafiee J, Wang Z, Song H, Yu Z-Z, Koratkar N. Enhanced Mechanical Properties of Nanocomposites at Low Graphene Content. ACS Nano. 2009;3(12):3884-90.

[28] Zhao X, Zhang Q, Chen D, Lu P. Enhanced mechanical properties of graphene-based poly (vinyl alcohol) composites. Macromolecules. 2010;43(5):2357-63. 
[29] Li Z, Young RJ, Wang R, Yang F, Hao L, Jiao W, et al. The role of functional groups on graphene oxide in epoxy nanocomposites. Polymer. 2013;54(21):5821-9.

[30] Zhang J, Jiang D. Molecular dynamics simulation of mechanical performance of graphene/graphene oxide paper based polymer composites. Carbon. 2014;67:784-91.

[31] Compton OC, Cranford SW, Putz KW, An Z, Brinson LC, Buehler MJ, et al. Tuning the mechanical properties of graphene oxide paper and its associated polymer nanocomposites by controlling cooperative intersheet hydrogen bonding. Acs Nano. 2012;6(3):2008-19.

[32] Li W, Tang X-Z, Zhang H-B, Jiang Z-G, Yu Z-Z, Du X-S, et al. Simultaneous surface functionalization and reduction of graphene oxide with octadecylamine for electrically conductive polystyrene composites. Carbon. 2011;49(14):4724-30.

[33] Xu Y, Hong W, Bai H, Li C, Shi G. Strong and ductile poly(vinyl alcohol)/graphene oxide composite films with a layered structure. Carbon. 2009;47(15):3538-43.

[34] Bao C, Guo Y, Song L, Kan Y, Qian X, Hu Y. In situ preparation of functionalized graphene oxide/epoxy nanocomposites with effective reinforcements. Journal of Materials Chemistry. 2011;21(35):13290.

[35] Chen L, Chai S, Liu K, Ning N, Gao J, Liu Q, et al. Enhanced epoxy/silica composites mechanical properties by introducing graphene oxide to the interface. ACS applied materials \& interfaces. 2012;4(8):4398-404.

[36] Wan Y-J, Tang L-C, Gong L-X, Yan D, Li Y-B, Wu L-B, et al. Grafting of epoxy chains onto graphene oxide for epoxy composites with improved mechanical and thermal properties. Carbon. 2014;69:467-80.

[37] Wang R, Li Z, Liu W, Jiao W, Hao L, Yang F. Attapulgite-graphene oxide hybrids as thermal and mechanical reinforcements for epoxy composites. Composites Science and Technology. 2013;87:29-35. 
[38] Fan Y, Estili M, Igarashi G, Jiang W, Kawasaki A. The effect of homogeneously dispersed few-layer graphene on microstructure and mechanical properties of A12O3 nanocomposites. Journal of the European Ceramic Society. 2014;34(2):443-51.

[39] Liu J, Yan H, Reece MJ, Jiang K. Toughening of zirconia/alumina composites by the addition of graphene platelets. Journal of the European Ceramic Society. 2012;32(16):4185-93.

[40] S.Walker L, Marotto VR, Rafiee MA, Koratkar N, Corral EL. Toughening in Graphene Ceramic Composites. ACS Nano. 2011;5(4):3182-90.

[41] Mannov E, Schmutzler H, Chandrasekaran S, Viets C, Buschhorn S, Tölle F, et al. Improvement of compressive strength after impact in fibre reinforced polymer composites by matrix modification with thermally reduced graphene oxide. Composites Science and Technology. 2013;87:36-41.

[42] Yavari F, Rafiee MA, Rafiee J, Yu ZZ, Koratkar N. Dramatic increase in fatigue life in hierarchical graphene composites. ACS applied materials \& interfaces. 2010;2(10):2738-43.

[43] Zhang X, Fan X, Yan C, Li H, Zhu Y, Li X, et al. Interfacial microstructure and properties of carbon fiber composites modified with graphene oxide. ACS applied materials \& interfaces. 2012;4(3):1543-52.

[44] Hummers Jr WS, Offeman RE. Preparation of graphitic oxide. Journal of the American Chemical Society. 1958;80(6):1339-.

[45] Chen Y, Song B, Tang X, Lu L, Xue J. One-step synthesis of hollow porous Fe 3 O 4 beads-reduced graphene oxide composites with superior battery performance. Journal of Materials Chemistry. 2012;22(34):17656-62.

[46] Gupta A, Chen G, Joshi P, Tadigadapa S, Eklund P. Raman scattering from high-frequency phonons in supported n-graphene layer films. Nano letters. 2006;6(12):2667-73.

[47] Park S, Lee K-S, Bozoklu G, Cai W, Nguyen ST, Ruoff RS. Graphene oxide papers modified by divalent ions-enhancing mechanical properties via chemical cross-linking. ACS nano. 2008;2(3):572-8. 
[48] Peng E, Choo ESG, Chandrasekharan P, Yang CT, Ding J, Chuang KH, et al. Synthesis of manganese ferrite/graphene oxide nanocomposites for biomedical applications. Small. 2012;8(23):3620-30.

[49] JIS K. 7086: 1993. Testing methods for interlaminar fracture toughness of carbon fibre reinforced plastics. 1993.

[50] Hojo M, Ando T, Tanaka M, Adachi T, Ochiai S, Endo Y. Modes I and II interlaminar fracture toughness and fatigue delamination of CF/epoxy laminates with self-same epoxy interleaf. International Journal of Fatigue. 2006;28(10):1154-65.

[51] Wang W, Takao Y, Matsubara T, Kim H. Improvement of the interlaminar fracture toughness of composite laminates by whisker reinforced interlamination. Composites science and technology. 2002;62(6):767-74.

[52] Yokozeki T, Iwahori Y, Ishiwata S, Enomoto K. Mechanical properties of CFRP laminates manufactured from unidirectional prepregs using CSCNT-dispersed epoxy. Composites Part A: Applied Science and Manufacturing. 2007;38(10):2121-30.

[53] Ning H, Li Y, Li J, Hu N, Liu Y, Wu L, et al. Toughening effect of CB-epoxy interleaf on the interlaminar mechanical properties of CFRP laminates. Composites Part A: Applied Science and Manufacturing. 2015;68:226-34.

[54] Hu N, Zemba Y, Fukunaga H, Wang H, Elmarakbi A. Stable numerical simulations of propagations of complex damages in composite structures under transverse loads. Composites science and technology. 2007;67(3):752-65.

[55] Hu N, Zemba Y, Okabe T, Yan C, Fukunaga H, Elmarakbi A. A new cohesive model for simulating delamination propagation in composite laminates under transverse loads. Mechanics of Materials. 2008;40(11):920-35.

[56] Liang W, Rui-Xiang B, Cheng Y. Interfacial debonding behavior of composite beam/plates with PZT patch. Composite Structures. 2010;92(6):1410-5. 
[57] Rafiee MA, Rafiee J, Srivastava I, Wang Z, Song H, Yu ZZ, et al. Fracture and fatigue in graphene nanocomposites. Small. 2010;6(2):179-83.

[58] Bortz DR, Heras EG, Martin-Gullon I. Impressive fatigue life and fracture toughness improvements in graphene oxide/epoxy composites. Macromolecules. 2011;45(1):238-45.

[59] Paci JT, Belytschko T, Schatz GC. Computational studies of the structure, behavior upon heating, and mechanical properties of graphite oxide. The Journal of Physical Chemistry C. 2007;111(49):18099-111. 